\title{
Modification of Alkali Activated Blast Furnace Slag for Pothole Repairs
}

\author{
Minna Sarkkinen ${ }^{1, *}$, Kauko Kujala ${ }^{2}$, and Seppo Gehör ${ }^{2}$ \\ ${ }^{1}$ Kajaani University of Applied Sciences, Department of Mechanical and Mining Engineering, FI-87101, Finland \\ ${ }^{2}$ Solid Liner Ltd, Finland
}

\begin{abstract}
Potholes denote small, typically sharp edged holes in the pavement. The aim of this research was to study the usability of alkali activated (AA) blast furnace slag based material in the repair of paved roads, especially during the cold winter and spring seasons when such repairs are needed most and the use of hot asphalt is not possible. The objective was to a find material which is both more cost-efficient and durable than plain cold asphalt. Properties like rapid strength development, good bonding with old paving material, weather resistance, abrasion resistance, and low shrinkage were required. The influence of the chosen factors on the performance of the material was studied applying the multi-attribute optimization method. The impact of different additives, such as Portland cement, fibers and crushed tire rubber were studied. The results indicated that the AA slag based materials studied can be improved by suitable additives to make them reach desired performance. According to the tests, adding Portland cement increased compressive strength threefold after 3 hours and reduced shrinkage by $34 \%$ but should be a negative impact on higher levels related to freeze-thaw resistance. In addition, crushed rubber was indicated to have a positive impact related to all the studied performance properties.
\end{abstract}

\section{Introduction}

Pothole denotes small, typically sharp edged holes in the pavement hampering traffic. They have become more common due to climate change and the consequent increasing amount of freeze-thaw cycles not only in Nordic countries. There are several different identified pavement damage types, which have been reported in earlier studies (e.g. [1-3]). The reasons for such damage are diverse and interrelated, the most common being traffic and weather stress (temperature, freezing and thawing, precipitation), and the structural weight of the road structures. In addition to the traffic load, water ingress through the pavement is a prerequisite for pothole formation. The holes are typically initiated after damage enables water ingress through the pavement. It is commonly believed that repeated freezing and thawing cycles accelerate pothole formation due to increased pressure during the freezing period and an oversaturated state under the pavement during the warmer period.

\section{Experimental}

The experiment used ground granulated blast furnace slag (BFS) as the principal solid binder and alkali solution based on potassium hydroxide and silicate as the main activator. The material type is classified as alkali activated cement because the major reaction product is calcium silicate hydrate (C-A-S-H) that is close to C-S-H reaction products formed in the hydration of ordinary Portland cement [4].

BFS is the most commonly used raw material in the manufacture of alkali activated cements. The quality of BFS depends on the production process and not all slags are suitable for alkali activation. For example, it has been stated that BFS should be granulated or pelletized and it should have a glassiness degree of $85-95 \%$ [5]. In addition, the ratio $\mathrm{CaO}+\mathrm{MgO} / \mathrm{SiO}_{2}$ should be above 1 , the glass polymerization degree should be low enough, and the fineness of the slag should be $400-600 \mathrm{~m}^{2} / \mathrm{kg}$.

\subsection{Design of experiment}

The experimental study applied the Taguchi method which separates system, parameter and tolerance design [6]. The system design in this study refers to the optimization of the material concept, in particular the optimization of the chosen parameters in relation to determined functional factors. The aim of the parameter design was to identify the optimal material composition. In the Taguchi design, robustness is achieved by identifying the control factors that reduce variability in the material and minimize the effects of noise. Noise factors

\footnotetext{
* Corresponding author: minna.sarkkinen@kamk.fi
} 
are manipulated to force variability during the Taguchi experiment in order to identify the optimal setting to gain robustness and resistance [7]. Higher signal to noise (S/N) ratios indicate optimal control factor settings and reduce the effects of noise. Extreme response values can be achieved by the optimal grouping of noise factors. Compounding can reduce the number of tests when the primary objective is not to estimate the effects of individual noise factors. Taguchi design uses orthogonal arrays which help to reduce the number of experiments required. The test series used in this study is based on the orthogonal matrix $\mathrm{L}^{9}$, with 3 levels.

Patching material can be considered as a system where different constituents interact with each other. The study focused on four factors: BFS to aggregate ratio, the impact of OPC and crushed tire rubber $(0-8 \mathrm{~mm})$ as additives, and the use of basalt fibers $(100 \mathrm{~mm})$ instead of plastic fibers while the other factors were kept constant. The test series comprised ground BFS and potassium hydroxide $(\mathrm{KOH}$ $10 \mathrm{M}$ ) and a Na-silicate (ca. $25 \%$ solution) based alkali activator as the main binder components. The AA solution (Na-silicate:KOH 2:1) was kept constant. The BFS derived from the SSAB iron plant in Finland. The aggregate was a crushed ferrochrome by-product derived from the Outokumpu steel plant in Finland. The impact of OPC and crushed tire rubber as additives, and the addition of basalt fibers and binder to aggregate ratio were used as changing factors with three levels. Table 1.

Table 1. Changing factors in the experiment.

\begin{tabular}{|c|c|c|c|c|}
\hline & Changing factor & L1 & L2 & L3 \\
\hline A & BFS to aggregate ratio & 1 & 0.7 & 0.5 \\
\hline B & OPC (w\%/(BFS+OPC) $)$ & 0 & 12.5 & 25 \\
\hline C & $\begin{array}{c}\text { Crushed tire rubber } \\
\text { (w\%) }\end{array}$ & 0 & 4 & 8 \\
\hline D & Basalt fiber (w\%) & 0 & 0.1 & 0.2 \\
\hline
\end{tabular}

The responses were studied in 13 performance properties, of which 4 are presented in this context (Table 2).

Table 2. Studied performance properties in the experiment.

\begin{tabular}{|c|c|}
\hline Investigated response & Method \\
\hline $\begin{array}{c}\text { Compressive strength after } \\
\text { 3h at temperatures } 20^{\circ} \mathrm{C} \\
\text { and }-10^{\circ} \mathrm{C}\end{array}$ & SFS-EN 12390-3 \\
\hline $\begin{array}{c}\text { Transformation } \\
\text { (shrinkage) }\end{array}$ & $\begin{array}{c}\text { length change in } \\
\text { prisms } 40 \times 40 \times 160 \\
\text { mm }\end{array}$ \\
\hline $\begin{array}{c}\text { Freeze-thaw resistance: } \\
\text { change in bonding and } \\
\text { compressive strength }\end{array}$ & $\begin{array}{c}50 \text { cycles (SFS-5447) } \\
\text { Stud abrasion resistance }\end{array}$ \\
\hline
\end{tabular}

\subsubsection{Early compressive strength}

Compressive strength development is an important indicator of material durability against the mechanical stresses caused by traffic. Rapid hardening and strength development is also required of pavement patching materials in low temperatures of $-5^{\circ} \mathrm{C}$ or below. Requirements for early compressive strength values vary. The compressive strength of rapidly hardening pavement patching materials should be evaluated no later than 24 hours according to some guidelines. Generally, the setting time should be less than 1 hour and the compressive strength should be at least $3.5 \mathrm{MPa}$ after 3 hours [8]. Compressive strength was evaluated applying the standard SFS-EN 12390-3by using 100x100x100 mm cubes stored uncovered at $20^{\circ} \mathrm{C}$ or $-10^{\circ} \mathrm{C}$ in the air [9].

\subsubsection{Weather resistance}

Alkali activated materials are porous and thus vulnerable to frost deterioration. Pore structure, volume, shape and distribution influence how water behaves in the material. The pores are comprised of gel pores $(0.5-2.5 \mathrm{~nm})$, which are too small for water molecules and larger capillary pores, which affect the permeability of water and other solutions [4]. It has been stated that the permeability of AA materials in general is lower than that of normal cement. There is still little research data on the pore structure of AA materials. However, it is known that several factors such as activator type, the ratio between solution and solid binder, curing conditions (temperature, relative humidity, time), and water content affect the pore structure.

Results for the frost resistance of AA materials vary [5]. A reason may be changed in the microstructure as a result of the differences in the constituents used and curing conditions. The frost resistance of AA materials can be enhanced by optimizing pore structure and increasing compressive strength. Optimal pore structure can prevent deterioration due to frost stress. A sufficient number of protective pores and limited distribution are required to guarantee good frost resistance. The most common method to optimize pore structure is to use an air entraining agent (AEA). However, opinions on the efficiency of AEA with AA materials are diverse and the research results vary according to the type of AEA used. According to some studies the need for AEA may be higher, but it does not guarantee better frost resistance [10]. AEA was not used in the test mixes in this study.

Freeze thaw cycles typically lead to internal cracking and strength loss in patching materials. The freeze-thaw test indicates the durability of patching materials in conditions where the temperature changes quickly and under freeze-thaw stress. The test helps to predict the sensitivity of the materials to disintegrate as a result of the climate. Damage is typically assessed based on changes in elastic modulus and strength. This study applied freezethaw resistance tests designed for concrete structures where temperature varied between 30 and $-20^{\circ} \mathrm{C}$, and the relative humidity RH between 0 and $100 \%$. The test was executed in a climate chamber. The weather resistance of the AA materials was tested by applying standard SFS5447 [11]. The deterioration grade was estimated by comparing the change in compressive and bonding strengths before and after the tests. 


\subsection{Batching and the testing specimen preparation}

The trial mixes were mixed using a Hobart blade mixer. The Mix amounted to ca. 4-5 kg, enough to fill two (100 x 100 x $100 \mathrm{~mm}$ ) cube molds. The dry mix components were mixed before adding alkali solution. The test mixes were compacted for two minutes using a vibrating table. The test specimens were stored uncovered at room temperature ca. $20^{\circ} \mathrm{C}$ or placed directly into the freezer adjusted to $-10^{\circ} \mathrm{C}$.

\section{Results and discussion}

The effect of the factors was evaluated using Minitab software, in relation to means and $\mathrm{S} / \mathrm{N}$ ratios. The $\mathrm{S} / \mathrm{N}$ ratio describes the relation between the levels of the factor and the average response based on the delta value. The mean value in Taguchi design indicates the average response for each combination of control factor levels in the design. The delta value indicates the change of the value between the highest and lowest average-response level in relation to the factor in question. The ranking order is based on the delta values: a rank of 1 indicates the highest delta value. The ranking order of the $\mathrm{S} / \mathrm{N}$ ratios and means indicate the relative importance of each factor to the response.

\subsection{Early compressive strength development} Initial compressive strength development was evaluated after 3 hours from casting and storing the specimens at two temperatures $\left(20^{\circ} \mathrm{C}\right.$ and $\left.-10^{\circ} \mathrm{C}\right)$ Fig 1 .

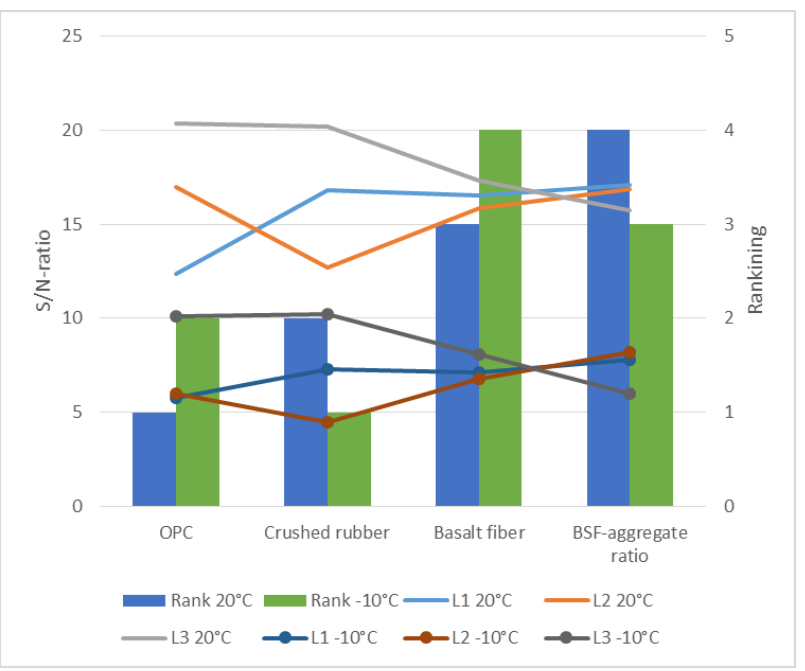

Fig. 1. Factor impact related to early compressive strength development. OPC and crushed rubber had the most positive impact at both temperatures.

The factors which had the most positive influence were $\mathrm{OPC}$ and crushed tire rubber at both temperatures. Higher OPC addition provided a threefold higher compressive strength at $20^{\circ} \mathrm{C}$ and double at $-10^{\circ} \mathrm{C}$. The range of the values were between 2,4 and $16,2 \mathrm{MPa}$ at $20^{\circ} \mathrm{C}$ and between 1,2 and $4,8 \mathrm{MPa}$ at $-10^{\circ} \mathrm{C}$ after 3 hours. $\mathrm{OPC}$ was more efficient at $20^{\circ} \mathrm{C}$ than crushed rubber, which had a slightly higher impact at $-10^{\circ} \mathrm{C}$. The higher BFS-aggregate ratio indicated a slight positive impact, which was more evident at $-10^{\circ} \mathrm{C}$. On the other hand, basalt fiber had a slightly negative impact with higher dosage on compressive strength at both temperatures. The reason for the impact of OPC lay most likely in change of pore structure which was denser due to the increased amount of reactants.

\subsection{Volumetric change}

Volumetric change due to drying shrinkage is a typical problem for AA BFS based materials. The issue is emphasized in patching materials where relatively strong AA is required in order to achieve rapid hardening under low temperature conditions. Shrinkage is sensitive to the curing environment, which is typically difficult to organize in road conditions where all traffic disturbances need to be minimized. In addition, it is known that waterglass as AA generates higher shrinkage than sodium hydroxide and drying shrinkage increases with higher AA dosage and higher fineness of BFS [12]. A stated reason for the shrinkage of AA BFS is high capillary stress due to a higher amount of mesopores compared to OPC [13].

The volumetric change of the test mixes was studied after 28 days storage in air $\left(20^{\circ} \mathrm{C}\right)$. The free shrinkage was measured using a length comparator to determine the linear dimension variation of the prism along the longitudinal axis. The first measurement was recorded immediately after demolding. The length change in the prisms was negative in all cases indicating shrinkage. Fig. 2.

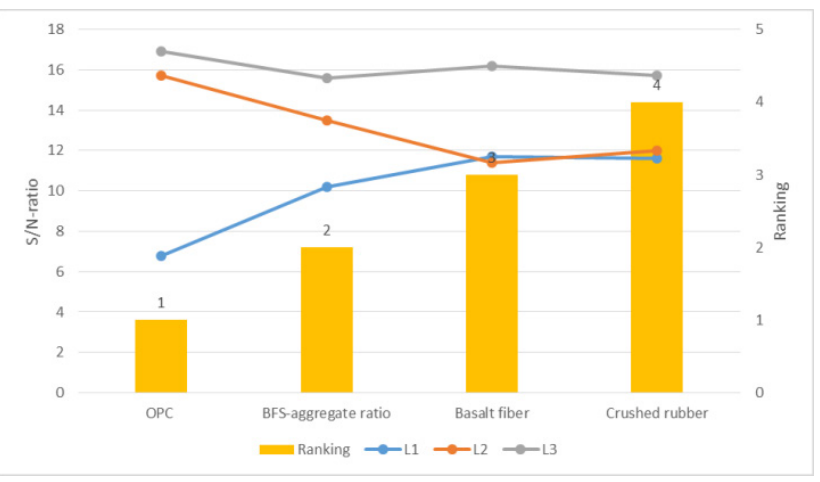

Fig. 2. Factor impact related to transformation. OPC had the highest positive impact on reducing length change.

All the studied factors reduced shrinkage with higher levels. The use of OPC had the highest positive impact on reducing length change above $34 \%$. The influence was already evident even with smaller amounts. The use of a lower BFS to aggregate ratio was also beneficial in reducing shrinkage. In addition, the use of crushed rubber and basalt fiber reduced shrinkage with higher amounts.

\subsection{Abrasion resistance}

Abrasion resistance was studied according to the so called PRALL test used for testing stud abrasion of asphalt pavements in Nordic countries. The test is executed at $5^{\circ} \mathrm{C}$ 
and the resistance is assessed according to mass loss during the test. Fig. 3

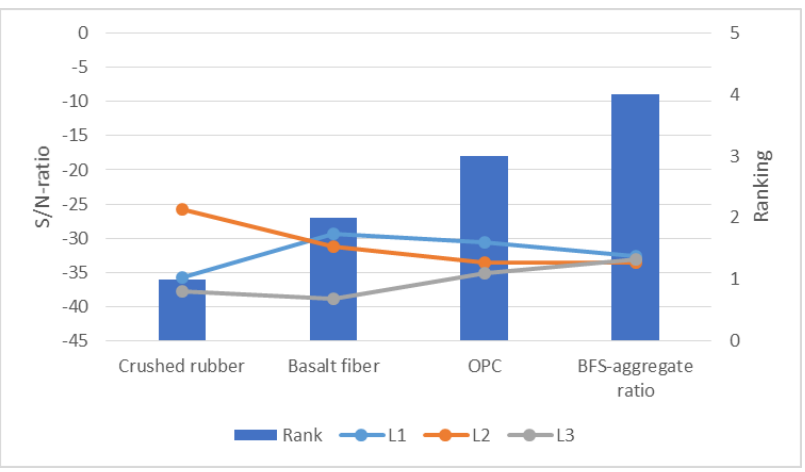

Fig. 3. Factor impact related to abrasion resistance. Crushed rubber and basalt fiber had the most positive impact on improving abrasion resistance.

According to the tests, crushed rubber and basalt fiber improved abrasion resistance when using higher amounts. The addition of OPC slightly improved abrasion resistance. On the other hand, the BFS to aggregate ratio had no clear impact on resistance. The test indicated that modified AA BFS material can meet the requirement for stud abrasion resistance stipulated for asphalt concretes. The test value $\mathrm{Abr}_{\mathrm{A}} 13.2 \mathrm{ml}$ achieved with higher rubber content was in the best abrasion class $\mathrm{Abr}_{\mathrm{A} 20}$.

\subsection{Freeze-thaw resistance}

The freeze-thaw resistance of the test mixes was evaluated in relation to compressive and bonding strength after 50 cycles. The results were calculated according to the ratio $\mathrm{R}_{\mathrm{A}} / \mathrm{R}_{\mathrm{B}}$ where $\mathrm{R}_{\mathrm{A}}$ indicated strength measured after the test and $R_{B}$ indicated the strength of the reference sample stored at $20^{\circ} \mathrm{C}$. Fig. 4 .

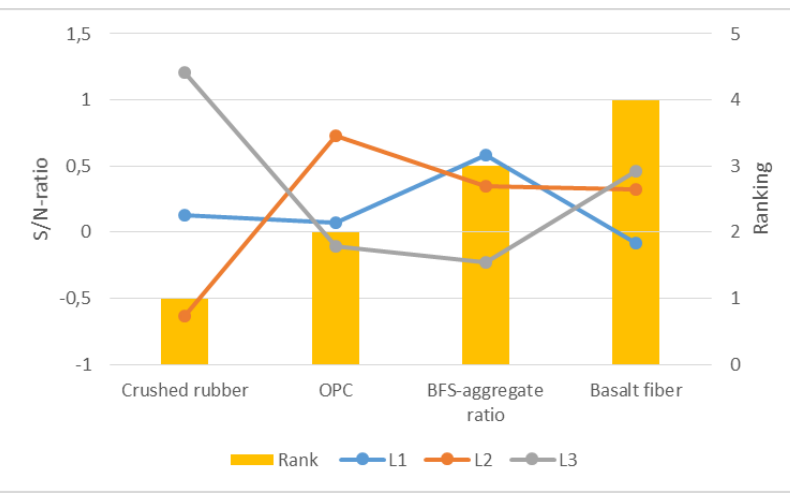

Fig. 4. Factors related to change in compressive strength after 50 freeze-thaw cycles. Crushed rubber had the highest positive impact on improving freeze-thaw resistance.

The use of crushed rubber as an additive had the highest effect concerning changes in compressive strength after 50 cycles i.e. a higher amount improved resistance. In addition, a higher BFS to aggregate ratio and use of basalt fiber improved compressive strength slightly. According to the test results, OPC reduced compressive resistance when using higher amounts.
Bonding strength was tested by applying a ca. $10 \mathrm{~mm}$ patch layer onto an old wet asphalt pavement slab. The surface of the asphalt was roughly cleared of loose debris by steel brush and moistened before the application. The bonding strength was measured with a pull-off testing machine by Matest (load capacity $16 \mathrm{kN}$ ) according to the EN 1542 (Measurement of bond strength by pull-off). When assessing freeze-thaw resistance related to bonding strength, the impact of the factors was slightly different compared to impact on compressive strength. Fig. 5.

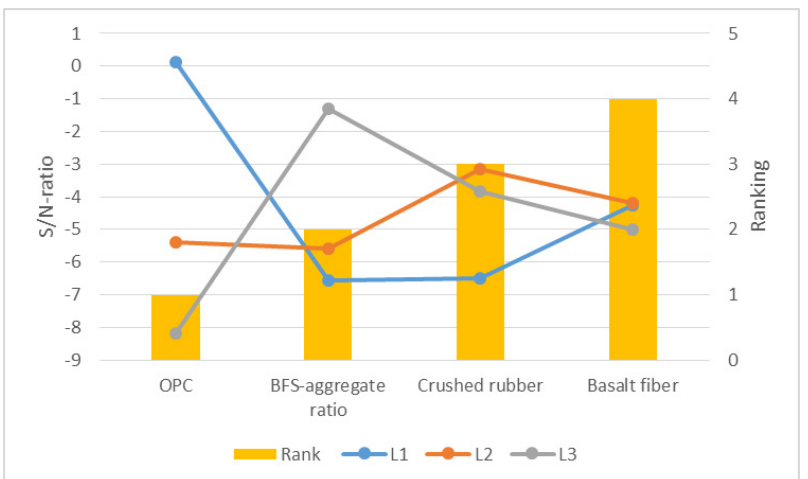

Fig. 5. Factor impact related to change in bonding strength after 50 freeze-thaw cycles. OPC had the highest impact on bonding strength but the impact was negative.

The use of OPC had the highest impact and the impact was negative by decreasing bonding strength after 50 cycles. The beneficial effect of higher aggregate content refers to the situation where no OPC is involved i.e. bonding to old asphalt is best achieved with plain AA BFS. Crushed rubber had a slightly positive impact on bonding strength while basalt fiber had no clear impact.

\section{Conclusions}

It can be concluded that the modified AA BFS material showed potential as an ecologically sustainable alternative for pavement patching comprising industrial by-products as the principal binder and aggregate components. In addition, recycled tire rubber was used as an additive. The results indicate that the modified AA BFS material can achieve good performance and durability in harsh weather conditions.

It could be observed that the use of OPC had a high impact on properties related to early strength development and reduced shrinkage. However, a high amount of OPC had side effects related to freeze-thaw resistance especially concerning bonding to old pavement. The use of crushed rubber as an additive positively impacted all the four performance properties. Higher BFS to aggregate content improved freeze-thaw resistance while a lower ratio was beneficial in reducing shrinkage. The BFS to aggregate ratio had only a minor effect on early strength development and abrasion resistance. According to the experiment, basalt fiber impacted positively with lower shrinkage and higher abrasion resistance and also had a minor positive impact on freeze-thaw resistance regarding compressive strength. 
According to the experiment, the recommended modified AA BFS patching material should only include a moderate amount of OPC as an additive ( $\max 12.5$ $\mathrm{w} \% / \mathrm{OPC}+\mathrm{BFS}$ ). The use of basalt fibers (e.g. $0.2 \mathrm{w} \%$ ) was beneficial and the use of crushed rubber as an additive could be recommended based on the studied material qualities.

Further experiments included, for example, research on factors influencing setting time, compressive and bonding strength development, salt-frost scaling resistance, water absorption, slip resistance, flexural strength, and microstructural studies. In addition, pilot tests were executed in four locations in Northern Finland.

\section{Acknowledgements}

The authors would like to thank Tekes - the Finnish Funding Agency for Innovation for their support.

\section{References}

1. P.Rajbongshi, S. Thongram, J. Eng. 2016, 7 (2016)

2. D.P. Orr, Cornell Local Roads Program, 17-40 (2006)

3. M.Tammirinne, A.Valkeisenmäki, E.Ehrola, Finnra Reports, 37/2002, 112 (2002)

4. F. Pacheco-Torgal, J.Labrincha, A.Leonelli, A. Palomo, P.Chindaprasit, Handbook of AlkaliActivated Cement Mortars and Concretes (Cambridge, Woodhead Publishing, 2015)

5. J.Provis, J.S. van Daventer, Geopolymers: structure, processing, properties (Cambridge, Woodhead Publishing, 2009)

6. R.A.Wysk, B.W. Niebel, B.W., P.H. Cohen, T.W. Simpson, Manufacturing Processes: Integrated Product and Process Design (McGraw Hill, New York, 2000)

7. B.-G. Irad, B.-G. IEEE Transactions on Reliability, 54, 381-388 (2005)

8. A. Ipavec, Del. No. 3, Project No. 832700 Durable Pothole Repairs (ZAG Slovenian National Building and Civ. Eng. Institute, Slovenia, 2012)

9. SFS-EN 12390-3 Testing hardened concrete. Part 3: Compressive strength of test specimens.

10. K.Byfors, T. Klingsted, V.Lehtonen, H.Pyy, H.L. Romben, Third International Conference on the Use of Natural Pozzolans, Fly Ash, Blast Furnace Slag and Silica Fume in Concrete, Trondheim, ACI, 14291466 (1989).

11. SFS 5447 Concrete. Durability. Freeze-thaw resistance.

12. A.A. Melo Neto, M.A. Cincotto, W. Repette, Cem Concr Res, 38, 565-574 (2008).

13. F.Collins, J.F. Sanjayan, Cem Conr Res, 30, 1401$1406(2000)$ 